\section{In search of the sublime}

\section{S. M. Walters}

The Garden of Eden: The Botanic Garden and the Re-creation of Paradise. By John Prest. Pp.122. ISBN 0-300-02726-5. (Yale University Press:1982.) $\$ 25, £ 12.50$.

AMONGST the ever-growing literature on the history of gardens, relatively little explicitly treats of botanic gardens and their place in the general development of horticultural ideas and practices. It is therefore of some interest to note the subtitle of John Prest's book, and to see how far the text which accompanies the lavish illustrations lives up to the promise. The thesis of the book is interesting, even novel: he traces the idea (or more strictly ideas) of Paradise in Christian thought and imagery as reflected in the design of gardens through the centuries, and places the sixteenth and seventeenth century botanic gardens firmly in this tradition. Whilst it is easy to agree that Christian images and influences were powerful in gardening history, the thesis does not wholly convince, for it underestimates the scientific and instructional aspects of the work of botanic gardens.

As befits an Oxford historian, the author has chosen the oldest botanic garden in England, that in his university, to illustrate the shape and scope of early botanic gardens, but it is surely too parochial altogether to ignore Kew except for a single, oblique reference. The final chapter, which discusses the breakdown of isolation of the hortus conclusus in the new climate of interest in nature and the natural world, is surely the place where Kew Gardens cries out for treatment. The interplay of botanic gardens with the great private gardens of the nobility is indeed a fascinating theme, but it is curiously and disappointingly undeveloped in this book.

The relationship between the plants and the animals in the Garden of Eden - one of the splendid illustrations in colour (also used on the dust-jacket) depicts this scene painted by Jan Brueghel - is touched on throughout the book, with the strong implication that it was only the sheer impractibility of including animals that prevented botanic gardens from being also zoos. This is surely a serious distortion of the history of botanic gardens, which arose largely to satisfy the needs of medical teaching in the universities. Although it is true that botanic gardens later took on the general function of displaying as wide a range of plants as possible, there is no evidence that they were ever seriously troubled by the vision that they might also display a correspondingly wide range of

A second edition of Sarnat and Netsky's Evolution of the Nervous System has been published by Oxford University Press, price £9.95. The first edition was reviewed in Nature 252, 428; 1974. representatives of the animal kingdom. Why should they, when systematic zoology was not taught in the universities, either to medical students or to anyone else?

It is perhaps inevitable that a book written by a historian on botanic gardens should say very little about the plants themselves, although they are the raison d'être of the institutions which grow them; when we find, however, that such few Latin scientific names as are used are mostly given incorrectly, with no capital letter for the generic name (as on pp.61 and 83 ), our confidence in the author's knowledge of this part of his subject is seriously undermined.

Undoubtedly, the author has read both widely and deeply in and around his subject, as the many footnotes, sensibly collected at the end together with the excellent bibliography, bear witness. As a source for further exploration of interesting themes, the book is quite exceptionally useful. The quality of paper, printing and reproduction of illustrations is very high, and the price, by 1982 standards, quite modest. A minor irritation is that many of the pages are unnumbered, because of the placing of illustration captions: this could surely have been avoided, without detriment to the very attractive design.

S. M. Walters is Director of the University Botanic Garden, Cambridge, and author of The Shaping of Cambridge Botany (Cambridge University Press, 1981).

\section{Chemical soul}

\section{A.G. Lee}

Liposomes: From Physical Structure to Therapeutic Applications. Edited by C.G. Knight. Pp.497. ISBN 0-444-80320-3. (Elsevier/North-Holland Biomedical: 1981.) $\$ 110.75$, Dfl. 260.

THE behaviour of suspensions of phospholipids in water (liposomes) has been under study for many years now, originally as a model for the lipid phase of biological membranes but more recently to investigate the possible therapeutic applications of liposomes in the delivery of drugs, enzymes and so on.

It was apparent by the late 1960 s that the fact that lipids formed sealed vesicles when dispersed in water meant that they might be used to trap and protect unstable compounds from a harmful environment and so, for example, might enable the oral administration of compounds that would otherwise be inactivated in the gastrointestinal tract. One possible advantage of liposomes for such a role is that since they are composed of "natural" compound, they might be expected to have little biological activity on their own. It has not turned out to be quite so simple. The problems, and attempts to overcome them, comprise the second part of this book.

Unfortunately, liposomes have antigenic properties, described in a chapter by Scherphof and co-workers. Patel and Ryman discuss the fate of liposomes when administered to animals, and Finkelstein and Weissmann describe attempts to target liposomes to specific tissues. An obvious problem raised in several chapters is that for liposomes to act as efficient drug delivery systems, drugs must not readily leak out of them. As discussed by Knight, this can in part be overcome by designing hydrophobic pro-drugs which are more likely to remain associated with the liposomes. In part also, it can be overcome by choosing components for the liposomes which will minimize their "fluidity". Nevertheless, the conclusion reached by Fildes is that the application of liposomes in the pharmaceutical industry is a long way off, because of a wide range of technical problems. At their most basic, liposomes would not be expected to last for very long in the average bathroom cabinet.

The overall impression of the second half of the book is then, as far as therapeutic applications are concerned, that liposomes are an answer awaiting a problem. With the first half of the book, we are on much more solid ground. This sets out to describe the physical properties of liposomes, with the aim of providing the information necessary for the proper design of liposomes for therapeutic applications. I imagine, however, that the book will be read mostly by those with an interest in biological membranes. It does provide an excellent, non-technical summary of our knowledge of the lipid bilayer, although the lack of discussion of the effects of proteins perhaps limits its general interest.

As is proper, the first chapter is a general introduction by Alex Bangham, who has done so much to generate the current interest in liposomes. A chapter by Eibl describes the synthetic routes to a wide range of phospholipids that he has developed based on reactions of phosphatidic acid dichlorides. We then have chapters on freeze-fracture studies, differential scanning calorimetry, X-ray, NMR and ESR. The latter chapter, as is appropriate for ESR, has an aura of mystery about it - the journal volume numbers given as $c<1 / 3, \sqcup 1 / 4, \cup(C)$ and even (c) $1 / 3(c)$ must be arcane cabalastic signs.

Finally, readers will have to decide for themselves whether or not Thudicum's description of lipids as "the centre, life and chemical soul of all bioplasm" (quoted by Bangham) is a little over the top.

A. $G$. Lee is a Lecturer in the Department of Biochemistry at the University of Southampton. 